\title{
Neonatal Auditory Brainstem Response Failure of Very Low Birth Weight Infants: 8-Year Outcome
}

\author{
CLARKE COX, MAUREEN HACK, DOROTHY ARAM, AND ELAINE BORAWSKI \\ Department of Otolaryngology, Boston University Medical Center, Boston, Massachusetts 02118 and Department \\ of Pediatrics, Rainbow Babies and Children's Hospital, Cleveland, Ohio 44106
}

\begin{abstract}
Fifty-six very low birth weight infants $(<1.5$ $\mathrm{kg}$ ) were followed until $8 \mathrm{y}$ of age to see if predischarge auditory brainstem response (ABR) results were predictive of neurobehavioral development. The results suggest that early ABR may predict subsequent performance on measures of intelligence quotient, language, and reading. Unilateral ABR abnormalities did not appear predictive, but bilateral abnormalities did. Analysis of a variety of neonatal risk factors in conjunction with early ABR and hearing loss with respect to educational outcome was also undertaken. (Pediatr Res 31: 68-72, 1992)
\end{abstract}

\section{Abbreviations}

ABR, auditory brainstem response

VLBW, very low birth weight

IQ, intelligence quotient

I-V, ABR interpeak latency

ANOVA, analysis of variance

nHL, normal hearing level

Prematurity and VLBW predisposes the child to a number of neurologic, developmental, language, and educational sequelae (1-4). Although the number of surviving infants has increased in the past decade, premature births have remained relatively constant. The net result has been a greater number of children at risk for the previously mentioned problems. Fortunately, awareness of this occurrence has accentuated efforts for early identification, but intervention success has been restricted partly because many of these problems are not manifested until the child is enrolled in school. Efforts to identify those children who will have handicaps have not always been successful (5). The high incidence of learning disabilities seen at school age by children who were born preterm justifies the need for early identification efforts, however (6).

One of the more recent measures available for early identification of hearing loss and neural insult has been the ABR. The $A B R$ has proven to be a valuable tool in the identification of hearing and neurologic impairment, which may impact on language development and learning (7). Additionally, the ABR has proven useful in adults and children in detecting peripheral and central neuropathy and monitoring neural status during neurosurgery and head trauma (8).

Recent emphasis with the ABR has focused on the potential to predict delayed or impaired development. For example, Majnemer et al. (9) reported that neonatal ABR was predictive of abnormal neurologic findings at $1 \mathrm{y}$ of age, whereas the

Received November 21, 1990; accepted July 29, 1991.

Correspondence and reprints requests: L. Clarke Cox, Ph.D., Dept. of Otolaryngology, 720 Harrison Ave., Suite 601, Boston, MA 02118.

Supported by NIH Grant R01 HD20057, the Grant Foundation (1985-1990), and The Robert Wood Johnson Foundation (1975-1978). standard newborn clinical exam was not. Murray (10) reported that the ABR was predictive of impaired development up to 9 mo of age on measures of mental, motor, auditory, language, and neurologic development.

To this point all ABR studies dealing with neurobehavioral development have been limited to the first years of life for followup. The full predictive capability of ABR has not been fully assessed because of this limited time frame. To credibly establish development, measures of learning and school performance must be obtained. Although these data are not available until the child is older, these measures must be available if the ABR is to be established as a predictor of development.

The purpose of the present study was to follow VLBW $(<1.5$ $\mathrm{kg}$ ) children up to $8 \mathrm{y}$ of age to determine if the ABR is a good predictor of neurobehavioral development.

\section{MATERIALS AND METHODS}

Fifty-six VLBW children born during 1977 and 1978 who had neonatal ABR before discharge were followed until 8 y of age. These infants were drawn from a larger cohort study of 202 VLBW children who were being studied longitudinally on measures of physical growth, neurocognitive functioning and psychosocial adjustment. These children were initially treated in the neonatal intensive care unit at Rainbow Babies and Childrens Hospital and constituted part of the high-risk follow-up program at this institution. The 56 study children were drawn from an original sample of 76 infants from whom initial ABR data have been previously reported (11). At 8 y of age, $56(74 \%)$ were available for study. The remaining 20 infants either moved out of state or were lost to follow-up, or parents declined study participation. It should be noted that the initial ABR group of 76 children represented only a minor portion of the total group of 202 children because of the limited time frame of the original ABR study.

The subjects were grouped according to the predischarge ABR data. Those who exhibited responses to stimuli at 30 decibels $\mathrm{nHL}$ and whose I-V interpeak latency was within $2 \mathrm{SD}$ of normative data were labeled as normal ABR subjects. Fortythree infants fell into this group. Thirteen infants failed to meet the normal criteria and were placed in the abnormal ABR group. For primary data analysis, these 13 infants were divided into unilateral or bilateral ABR abnormality groups. For secondary analysis, these same 13 abnormal infants were divided into three different groups suggested by the type of ABR abnormality. Subjects with no observable wave forms at 95 decibels nHL were labeled as the no response group. Infants with prolonged I-V intervals were placed in the central group because presumably the ABR abnormality originated within the central auditory pathway. Infants who failed to exhibit wave forms at 30 decibels $\mathrm{nHL}$ but did so at higher intensities were placed in the peripheral group as long as the I-V interval was normal. Figure 1 illustrates one normal and three abnormal types of ABR responses generated by the study infants. Unilateral/bilateral abnormalities can 


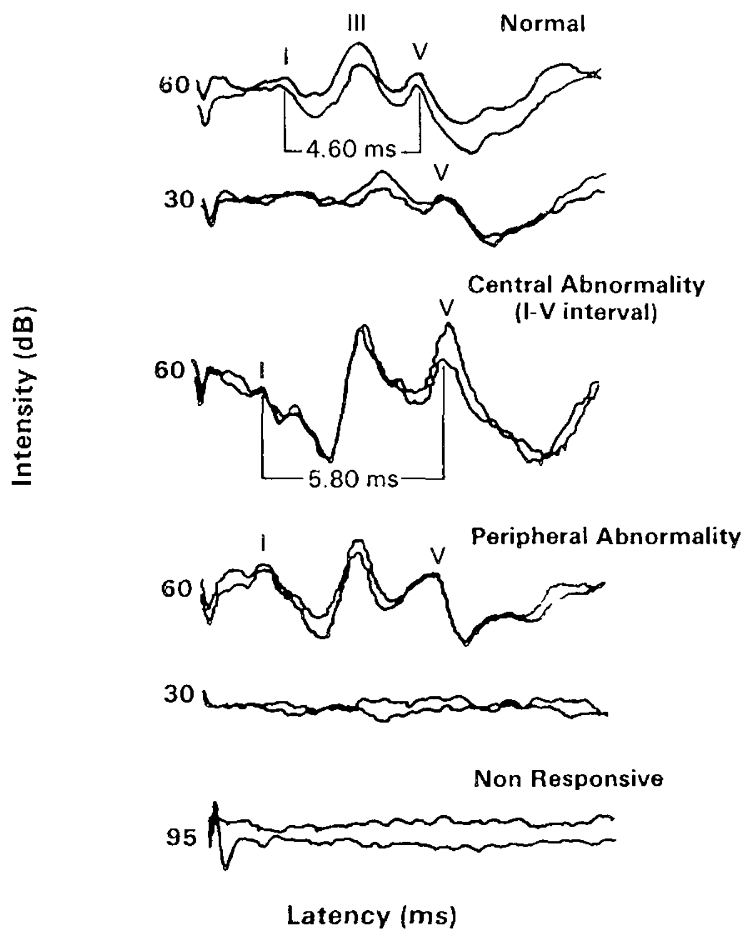

Fig. 1. Examples of the ABR response patterns.

be visualized by looking at the three abnormal examples with respect to whether the ABR abnormality occurred in one (unilateral) or both ears (bilateral).

Because of the already small $n$ for the group, no attempt was made to separate conductive from sensorineural hearing loss in the peripheral group. Furthermore, additional group separation, i.e. unilateral central versus bilateral central, unilateral peripheral, was not undertaken because of the small number of subjects in each of the analysis groups.

In regard to the secondary data analysis, the authors realize that independence is an important statistical property. It is understood that the primary and secondary groups are related, but believed that the potential for additional information outweighs the loss of pure statistical independence.

Test protocol for the predischarge ABR has been detailed elsewhere (11); consequently, only a brief outline will be given here. Testing was effected after feeding so that the infants remained quiet during data acquisition. Disc electrodes were taped to the forehead and mastoids. Clicks of $0.1 \mathrm{~ms}$ duration presented via a hand-held TDH-39 earphone (Telephonics Corp., Huntington, NY) at 33 clicks/s served as test stimuli. Two trials of 2100 sweeps were averaged and stored on a commercial averager. Input voltages were amplified $\left(10^{4}\right)$ and filtered $(150-1500 \mathrm{~Hz})$. Peak latencies were determined on-line and recorded numerically.

At 8 y of age, all subjects were given a battery of intelligence, speech, language, and academic measures. Multiple tests were administered to measure a comprehensive range of abilities. Tests were selected to be sensitive to subtle neurologic abnormalities. All measures are well-standardized with this age group and most have been used previously in studies of VLBW children.

Intelligence was measured by the Wechsler Intelligence Scale for Children-Revised; both the verbal and performance IQ were reported (mean $=100 ; \mathrm{SD}=15$ ). Four measures of language were included. The Token Test for Children measured children's ability to understand commands of increased length and syntactic complexity. The total raw score for all five subtests is reported here. The Model Sentences subtest of the Clinical Evaluation of Language Functions served as a measure of expressive sentence structure, with the raw score reported. The Rapid Automatized Naming Task provided a test of rapid word retrieval in which the seconds required to name five sets of 50 randomly ordered pictures of objects, letters, numbers or colors was recorded. The total time in seconds required for naming all five sets of pictures was reported. The Photo Articulation Test provided a test of speech articulation for which the raw number of sounds in error was given. Three measures of academic achievement were included, which were reported in standardized scores: the spelling subtest of the Wide Range Achievement Test; the math cluster score from the Woodcock-Johnson Psycho-Educational Battery; and three subtests from the Woodcock Reading Mastery Test including word attack (application of phonetic rules to oral reading of nonwords), word identification (oral reading of single meaningful words), and passage comprehension.

The data were grouped according to the ABR results. Primary and secondary data analyses were accomplished with a one-way ANOVA. Post hoc analyses were completed with the Tukey. A significance level of 0.05 was used in the analyses.

In addition to the specific measures of neurobehavioral development, ancillary variables of sociodemographic, perinatal, and later hearing loss were evaluated. These data were obtained to describe the sample and examine the existence of possible covariates. Sociodemographic variables of race, sex, social status (12), level of mother education, and age were recorded. Perinatal factors including birth weight, gestational age, cumulative neonatal risk score (13), asphyxia at 1 and $5 \mathrm{~min}$, apnea, and respiratory distress syndrome were obtained. Additional factors of hearing at $4 \mathrm{mo}$, approximately $24 \mathrm{mo}$, and $8 \mathrm{y}$ of age plus neurologic status at 20 mo and 8 y of age were also evaluated.

Hearing status at 4 mo was assessed with ABR and acoustic immittance. At 2 and $8 \mathrm{y}$ of age, appropriate behavioral measures were primarily used. Determination of hearing loss at $4 \mathrm{mo}$ occurred if the child failed to exhibit click ABR responses at 30 decibels nHL. A child was categorized with hearing loss if one or both ears met the criteria. At 2 and 8 y of age, children with behavioral thresholds greater than 25 decibels HL in the 1000 to $4000-\mathrm{Hz}$ range were classified as hearing impaired.

These ancillary data were analyzed with either a $t$ test or $\chi^{2}$. Although a probability level of 0.05 was chosen for the study, Bonferroni's adjustment was used to reduce the chance of type I error due to the multiple inference situation. All analyses including ANOVA and relative risk ratios were carried out with a SPSS/pc+ statistical package (SPSS Inc., Chicago, IL).

\section{RESULTS}

At birth, ABR testing produced 13 failures (six bilateral, seven unilateral). These $A B R$ failure children were compared to the normal group on neurobehavioral outcome. A summary of the ANOVA results for the primary analyses is shown in Table 1. Significant differences were seen on measures of IQ, language, and academic achievement. With the exception of the Rapid Automatized Naming Task, the Photo Articulation Test, and word identification, all measures reached significance. Post hoc analysis revealed that although scores of subjects with abnormal unilateral $\mathrm{ABR}$ results were lower than normals, only scores of subjects with bilateral abnormal ABR were significantly lower.

To further delineate the ABR data, secondary ANOVA was accomplished according to the subgroups noted previously, i.e. central, peripheral, or no response. As can be seen from the data shown in Table 2, measures of IQ and language were significant. The only significant measure of academic achievement was word attack. Post hoc analysis did not differentiate between the three categories, suggesting that no one ABR abnormality was more likely to produce abnormal neurobehavioral development.

As a measure of "real-life" outcome, data reporting children who repeated grades 1-3 were obtained. Seven children from the normal group (16\%) repeated a grade, and six of the 13 in the abnormal group $(46 \%)$ repeated a grade. In calculating the relative risk for grade repetition, normals, bilaterals, and unilaterals had relative risk ratios of $0.33,2.79$, and 3.18 , respectively. 
Table 1. All unilateral, bilateral ABR failures vs normal group*

\begin{tabular}{|c|c|c|c|c|c|c|c|c|}
\hline \multirow[b]{2}{*}{ Measure } & \multicolumn{2}{|c|}{$\begin{array}{l}\text { Normal ABR } \\
\quad(n=43)\end{array}$} & \multicolumn{2}{|c|}{$\begin{array}{l}\text { Unilateral } \\
\quad(n=6)\end{array}$} & \multicolumn{2}{|c|}{$\begin{array}{c}\text { Bilateral } \\
(n=7)\end{array}$} & \multirow{2}{*}{$\begin{array}{c}F \\
\text { ratio }\end{array}$} & \multirow{2}{*}{$\begin{array}{c}F \\
\text { probability }\end{array}$} \\
\hline & Mean & $\mathrm{SD}$ & Mean & $\mathrm{SD}$ & Mean & SD & & \\
\hline \multicolumn{9}{|l|}{ IQ (WISC-R) } \\
\hline Verbal & 93.09 & 16.9 & 81.33 & 21.8 & 78.86 & 10.0 & 4.62 & $0.014 \dagger$ \\
\hline Performance & 96.47 & 16.2 & 86.17 & 15.6 & 74.86 & 9.0 & 6.48 & $0.003 \dagger$ \\
\hline \multicolumn{9}{|l|}{ Language } \\
\hline Token (total raw score) & 52.72 & 5.2 & 46.67 & 9.8 & 44.86 & 10.6 & 5.28 & $0.008 \dagger$ \\
\hline CELF (raw score) & 39.23 & 7.7 & 31.67 & 9.4 & 30.71 & 16.4 & 3.82 & 0.028 \\
\hline RAN (total seconds) & 195.46 & 67.7 & 193.25 & 52.4 & 219.16 & 53.4 & 0.42 & 0.658 \\
\hline \multicolumn{9}{|l|}{ Speech } \\
\hline PAT (no. of errors) & 2.19 & 4.9 & 4.33 & 7.4 & 7.00 & 12.7 & 1.77 & 0.179 \\
\hline \multicolumn{9}{|l|}{ Academic achievement } \\
\hline Spelling: WRAT (std) & 90.05 & 14.8 & 83.17 & 23.8 & 68.67 & 14.5 & 4.96 & $0.011 \dagger$ \\
\hline Math: WJPB-Cluster (std) & 95.41 & 13.6 & 88.83 & 21.0 & 79.14 & 9.6 & 4.23 & $0.020 \dagger$ \\
\hline \multicolumn{9}{|l|}{ Reading (std) } \\
\hline Word attack & 89.23 & 17.8 & 81.67 & 24.8 & 65.43 & 19.4 & 5.01 & $0.010 \dagger$ \\
\hline Word identification & 95.09 & 18.9 & 91.17 & 24.9 & 77.00 & 16.2 & 2.67 & 0.079 \\
\hline Passage comprehension & 93.16 & 17.8 & 84.67 & 18.6 & 71.72 & 19.6 & 4.46 & $0.016 \dagger$ \\
\hline
\end{tabular}

* WISC-R, Wechsler Intelligence Scale for Children-Revised; Token, Token Test for Children; CELF, Clinical Evaluation of Language Functions; RAN, Rapid Automatized Naming Task; PAT, Photo Articulation Test; WRAT, Wide Range Achievement Test; WJPB, Woodcock-Johnson Psycho-Educational Battery; std, standardized scores.

$\dagger$ Significant differences (Tukey $p<0.05$ ) between normal ABR and bilateral groups.

Table 2. All central, peripheral, and no response vs normal group*

\begin{tabular}{|c|c|c|c|c|c|c|c|c|c|c|}
\hline \multirow[b]{2}{*}{ Measure } & \multicolumn{2}{|c|}{$\begin{array}{c}\text { Normal ABR } \\
\quad(n=43)\end{array}$} & \multicolumn{2}{|c|}{$\begin{array}{l}\text { Central } \\
(n=4)\end{array}$} & \multicolumn{2}{|c|}{$\begin{array}{l}\text { Peripheral } \\
\quad(n=5)\end{array}$} & \multicolumn{2}{|c|}{$\begin{array}{l}\text { No response } \\
\quad(n=4)\end{array}$} & \multirow{2}{*}{$\begin{array}{c}F \\
\text { ratio }\end{array}$} & \multirow{2}{*}{$\begin{array}{c}F \\
\text { probability }\end{array}$} \\
\hline & Mean & SD & Mean & SD & Mean & SD & Mean & $\mathrm{SD}$ & & \\
\hline \multicolumn{11}{|l|}{ IQ (WISC-R) } \\
\hline Verbal & 96.09 & 16.9 & 83.00 & 23.6 & 78.00 & 6.7 & 79.5 & 19.0 & 3.07 & 0.036 \\
\hline Performance & 96.47 & 16.1 & 77.25 & 15.3 & 78.00 & 5.3 & 85.5 & 19.4 & 3.83 & 0.015 \\
\hline \multicolumn{11}{|l|}{ Language } \\
\hline Token (total raw score) & 52.72 & 5.2 & 46.00 & 14.4 & 48.40 & 6.3 & 43.50 & 10.7 & 3.17 & $0.017 \dagger$ \\
\hline CELF (raw score) & 39.23 & 7.7 & 32.75 & 12.5 & 35.60 & 11.6 & 24.00 & 15.7 & 3.95 & $0.013 \dagger$ \\
\hline RAN (total seconds) & 195.46 & 67.7 & 183.85 & 24.7 & 221.31 & 70.8 & 212.93 & 51.1 & 0.36 & 0.778 \\
\hline \multicolumn{11}{|l|}{ Speech } \\
\hline PAT (no. of errors) & 2.19 & 4.9 & 1.00 & 1.4 & 6.20 & 8.0 & 10.00 & 16.7 & 2.39 & 0.079 \\
\hline \multicolumn{11}{|l|}{ Academic achievement } \\
\hline Spelling: WRAT (std) & 90.05 & 14.8 & 79.33 & 33.6 & 75.80 & 9.5 & 73.50 & 24.7 & 2.39 & 0.078 \\
\hline Math: WJPB-Cluster (std) & 95.41 & 13.6 & 83.25 & 22.7 & 84.00 & 4.0 & 83.5 & 21.9 & 2.20 & 0.099 \\
\hline \multicolumn{11}{|l|}{ Reading (std scores) } \\
\hline Word attack & 89.23 & 17.8 & 82.50 & 25.5 & 68.00 & 10.2 & 69.50 & 33.0 & 2.92 & 0.042 \\
\hline Word identification & 95.09 & 18.9 & 87.75 & 26.9 & 82.60 & 5.8 & 80.50 & 31.0 & 1.23 & 0.305 \\
\hline Passage comprehension & 93.16 & 17.8 & 83.25 & 21.6 & 78.60 & 4.7 & 71.00 & 30.4 & 2.65 & 0.058 \\
\hline
\end{tabular}

* Abbreviations used are defined in Table 1 .

$\dagger$ Significant differences (Tukey $p<0.05$ ) between normal ABR and no response groups.

In an effort to gather additional information on outcome, sociodemographic, perinatal and later developmental factors were evaluated (Table 3 ). Each factor was compared statistically ( $\chi^{2}$ where appropriate and $t$ tests) to see if any were associated with the ABR failure group. Although trends occurred, significant differences were not seen after using Bonferroni's correction.

Because hearing loss is well established as a factor related to neurobehavioral development, it was evaluated independently. As noted previously, measures of hearing were taken at 4 mo, 2 $y$, and 8 y of age. At $4 \mathrm{mo}$, only two children met the criteria for hearing loss, although several had abnormal acoustic immittance results. Follow-up testing of these two children confirmed one with a bilateral mild sensorineural hearing loss and the other with a unilateral moderate sensorineural loss. At $2 \mathrm{y}$ of age, seven children and, at $8 \mathrm{y}$, eight children exhibited elevated thresholds. Only the two children identified at 4 mo had sensorineural hearing loss at 2 and $8 \mathrm{y}$. The remaining children who failed their hearing tests (five at $2 \mathrm{y}$ and six at $8 \mathrm{y}$ ) exhibited transient conductive hearing loss typically associated with middle ear disorder (otitis media).

To determine if hearing loss had an impact on neurobehavioral development, statistical analysis was carried out. The data shown in Table 4 suggest that the groups differed significantly only on measures of spelling and reading across all three age groups.

\section{DISCUSSION}

The present study was designed to see if early ABR could predict neurobehavioral development. In the areas of IQ, language, and academic achievement, it appears that this prediction capability may exist. Potentially, $\mathrm{ABR}$ abnormality may predict later performance in the three areas noted above.

The results noted in the primary analyses are viewed by the present authors with a high degree of confidence. Results revealed by the secondary analyses are viewed with less confidence because of the small number of subjects associated with each group. If 
Table 3. ABR results associated with sociodemographics, perinatal, and developmental factors

\begin{tabular}{|c|c|c|c|c|}
\hline & $\begin{array}{c}\text { Normal ABR } \\
\quad(n=43)\end{array}$ & $\begin{array}{c}\text { Abnormal ABR } \\
\quad(n=13)\end{array}$ & $\chi^{2} / t$ test & $p^{*}$ \\
\hline \multicolumn{5}{|l|}{ Sociodemographic risk factors } \\
\hline Maternal age $(y \pm S D)$ & $25 \pm 4$ & $23 \pm 5$ & 1.30 & 0.200 \\
\hline Maternal education: high school $(n, \%)$ & $8(18)$ & $2(15)$ & 2.92 & 0.231 \\
\hline \multicolumn{5}{|l|}{ Social class: Hollingshead (Ref. 12) } \\
\hline Class I-III $(n, \%)$ & $15(34)$ & $3(23)$ & 1.03 & 0.307 \\
\hline Class IV-V $(n, \%)$ & $29(65)$ & $4(76)$ & 1.05 & 0.311 \\
\hline Race: Caucasian $(n, \%)$ & $18(42)$ & $4(31)$ & 0.15 & 0.694 \\
\hline \multicolumn{5}{|l|}{ Hobel (Ref. 13) scores (mean \pm SD) } \\
\hline Prenatal & $12 \pm 14$ & $11 \pm 14$ & 0.17 & 0.863 \\
\hline Intrauterine & $17 \pm 13$ & $20 \pm 14$ & 0.75 & 0.458 \\
\hline Neonatal & $50 \pm 29$ & $70 \pm 31$ & 2.17 & 0.034 \\
\hline \multicolumn{5}{|l|}{ Infant birth data } \\
\hline Birthweight $(\mathrm{g} \pm \mathrm{SD})$ & $1185 \pm 214$ & $1063 \pm 224$ & 1.77 & 0.082 \\
\hline Gestational age ( $w k \pm S D)$ & $30.0 \pm 2.1$ & $28.7 \pm 1.8$ & 2.10 & 0.049 \\
\hline Intrauterine growth failure $(n, \%)$ & $13(30)$ & $4(31)$ & 0.44 & 0.514 \\
\hline Multiple birth $(n, \%)$ & $15(34)$ & $2(15)$ & 0.90 & 0.342 \\
\hline Sex: Male $(n, \%)$ & $22(50)$ & $9(69)$ & 1.09 & 0.294 \\
\hline \multicolumn{5}{|l|}{ Neonatal risk factors } \\
\hline Apgar $<6$ at $1 \min (n, \%)$ & $21(48)$ & $8(61)$ & 0.31 & 0.575 \\
\hline$<6$ at $5 \min (n, \%)$ & $4(9)$ & $4(31)$ & 2.31 & 0.127 \\
\hline Respiratory distress syndrome $(n, \%)$ & $29(66)$ & $11(85)$ & 5.57 & 0.232 \\
\hline Infection $(n, \%)$ & $4(9)$ & $3(23)$ & 0.75 & 0.384 \\
\hline Apnea of prematurity $(n, \%)$ & $12(27)$ & $6(61)$ & 3.97 & 0.048 \\
\hline Bilirubin (mg $\pm \mathrm{SD})$ & $9 \pm 2$ & $10 \pm 2$ & 0.96 & 0.383 \\
\hline \multicolumn{5}{|c|}{ Development during infancy and early childhood } \\
\hline \multicolumn{5}{|c|}{ Major neurologic abnormality $(n, \%)$} \\
\hline $20 \mathrm{mo}$ & $2(5)$ & $1(8)$ & 1.14 & 0.563 \\
\hline $8 y$ & $4(9)$ & $2(15)$ & 0.72 & 0.232 \\
\hline \multicolumn{5}{|l|}{ Bayley mental developmental index } \\
\hline 8 mo $($ mean $\pm \mathrm{SD})$ & $100 \pm 19$ & $94 \pm 15$ & 0.98 & 0.342 \\
\hline 20 mo $($ mean $\pm S D)$ & $95 \pm 20$ & $89 \pm 16$ & 1.01 & 0.342 \\
\hline \multicolumn{5}{|l|}{ Bayley psychomotor development index } \\
\hline 8 mo $($ mean $\pm S D)$ & $101 \pm 20$ & $99 \pm 19$ & 0.42 & 0.583 \\
\hline 20 mo $($ mean $\pm S D)$ & $92 \pm 15$ & $98 \pm 8$ & 0.97 & 0.356 \\
\hline
\end{tabular}

* No factor reached significance at 0.002 .

Table 4. All infants with hearing loss at 4 mo, $2 y$, and 8 y of age vs normal group*

\begin{tabular}{|c|c|c|c|c|c|c|c|c|c|c|c|c|}
\hline \multirow[b]{2}{*}{ Measure } & \multicolumn{4}{|c|}{$4 \mathrm{mo}$} & \multicolumn{4}{|c|}{$2 y$} & \multicolumn{4}{|c|}{$8 y$} \\
\hline & $\begin{array}{l}\text { Normal } \\
\text { hearing } \\
(n=54)\end{array}$ & $\begin{array}{c}\text { Hearing } \\
\text { loss } \\
(n=2)\end{array}$ & $t$ test & $p$ & $\begin{array}{l}\text { Normal } \\
\text { hearing } \\
(n=48)\end{array}$ & $\begin{array}{c}\text { Hearing } \\
\text { loss } \\
(n=8)\end{array}$ & $t$ test & $p$ & $\begin{array}{c}\text { Normal } \\
\text { hearing } \\
(n=49)\end{array}$ & $\begin{array}{c}\text { Hearing } \\
\text { loss } \\
(n=7)\end{array}$ & $t$ test & $p$ \\
\hline \multicolumn{13}{|l|}{ WISC-R (std) } \\
\hline Verbal & $93.2 \pm 17$ & $67.5 \pm 13$ & 2.06 & 0.044 & $94.9 \pm 17$ & $76.8 \pm 11$ & 2.81 & $0.007 \dagger$ & $93.5 \pm 18$ & $83.7 \pm 13$ & 1.38 & 0.174 \\
\hline Performance & $93.2 \pm 16$ & $76.0 \pm 22$ & 1.43 & 0.158 & $94.8 \pm 16$ & $79.7 \pm 14$ & 2.43 & 0.018 & $93.7 \pm 17$ & $84.8 \pm 12$ & 1.31 & 0.195 \\
\hline \multicolumn{13}{|l|}{ Language } \\
\hline Token V (raw) & $51.5 \pm 6$ & $43.0 \pm 5$ & 1.70 & 0.095 & $51.9 \pm 6$ & $46.6 \pm 8$ & 2.03 & 0.047 & $51.9 \pm 7$ & $48.4 \pm 5$ & 1.11 & 0.272 \\
\hline CELF (raw) & $38.2 \pm 8$ & $13.0 \pm 7$ & 4.10 & $0.001 \dagger$ & $39.1 \pm 7$ & $26.6 \pm 13$ & 2.57 & 0.034 & $38.5 \pm 8$ & $29.1 \pm 13$ & 2.50 & 0.015 \\
\hline \multicolumn{13}{|l|}{ Speech } \\
\hline $\begin{array}{l}\text { PAT (no. of er- } \\
\text { rors) }\end{array}$ & $2.4 \pm 5$ & $18.5 \pm 23$ & 0.97 & 0.509 & $1.8 \pm 4$ & $10.2 \pm 11$ & 2.01 & 0.083 & $2.3 \pm 4$ & $8.0 \pm 13$ & 2.20 & 0.032 \\
\hline \multicolumn{13}{|l|}{ Spelling } \\
\hline WRAT (std) & $88.1 \pm 15$ & $54.1 \pm 12$ & 2.94 & $0.005 \uparrow$ & $90.0 \pm 15$ & $68.8 \pm 15$ & 3.59 & $0.001 \dagger$ & $89.3 \pm 16$ & $70.5 \pm 13$ & 2.91 & $0.005 \dagger$ \\
\hline \multicolumn{13}{|l|}{ Math } \\
\hline WJPB (std) & $93.5 \pm 14$ & $67.0 \pm 2$ & 2.60 & 0.012 & $94.5 \pm 14$ & $81.1 \pm 10$ & 2.46 & 0.017 & $94.6 \pm 14$ & $78.4 \pm 8$ & 2.87 & 0.006 \\
\hline \multicolumn{13}{|l|}{ Reading (std) } \\
\hline Word attack & $86.9 \pm 18$ & $46.0 \pm 2$ & 3.04 & $0.004 \dagger$ & $89.6 \pm 17$ & $60.5 \pm 16$ & 4.39 & $0.001 \uparrow$ & $88.4 \pm 18$ & $64.1 \pm 17$ & 3.26 & $0.002 \uparrow$ \\
\hline $\begin{array}{l}\text { Word identifi- } \\
\text { cation }\end{array}$ & $93.7 \pm 18$ & $57.5 \pm 19$ & 2.67 & 0.010 & $95.7 \pm 18$ & $72.2 \pm 18$ & 3.39 & $0.001 \dagger$ & $94.7 \pm 14$ & $76.2 \pm 18$ & 2.40 & 0.020 \\
\hline $\begin{array}{l}\text { Passage com- } \\
\text { prehension }\end{array}$ & $90.9 \pm 18$ & $52.0 \pm 14$ & 3.01 & $0.004 \dagger$ & $92.6 \pm 16$ & $70.8 \pm 23$ & 3.21 & $0.002 \dagger$ & $91.8 \pm 17$ & $73.4 \pm 22$ & 2.48 & 0.016 \\
\hline
\end{tabular}

* Abbreviations used are defined in Table 1 .

$\dagger p<0.005$. 
cautious interpretation is exercised, however, it appears that additional delineation of the ABR results can occur.

The most obvious piece of information derived from the data analysis is that unilateral ABR abnormalities may not affect neurobehavioral development. Although this is not surprising based on traditional assumptions, recent data suggest otherwise (14). Bess et al. (15) have shown repeatedly that long-term unilateral hearing loss affects language-related performance. Although unilateral ABR abnormalities did not differ significantly, the trend for group differences coupled with the grade repetition data suggests that unilateral abnormalities not be ignored as possible predictors of development.

Bilateral ABR abnormalities on the other hand, do reflect neurobehavioral development. It would appear that the significant results seen in the primary ABR failure group were related to bilateral failures. Predictions of neurobehavioral development based on early ABR should focus on bilateral failures regardless of their location. Although secondary analyses failed to exhibit specific differences with central, no response, and peripheral ABR abnormalities, they should not be ignored as possible correlates of developmental anomalies. Furthermore, infants who initially fail the ABR screening bilaterally but later exhibit normal ABR patterns should not be abandoned without followup. Although it would be foolish and alarmist to label the child as abnormal, he or she may be at risk and should be followed to ascertain normal language development. Early measures of IQ and performance may also be in order so that the child may enjoy the benefits of early intervention.

In reviewing the data, questions arise particular to possible mechanisms underlying the results. We typically accept the notion that the ABR represents afferent neural activity conditioned by peripheral structures that is transmitted to higher auditory centers. Although ABR abnormalities may originate from either peripheral or central regions, they will in turn be delivered to higher auditory pathways. To the developing central auditory nervous system, disordered input from lower levels may impact development at higher levels. Furthermore, if these higher pathways experience disorder concomitant with lower level disorder (e.g. abnormal ABR), the net result may be synergistic in nature.

These developmental abnormalities would presumably be rather subtle and perhaps even subclinical. This is supported by ABR data that reveals that early abnormalities typically normalize by 4 mo of age. The transient abnormalities reflected by the ABR may be sufficient to influence the developing central auditory nervous system. Although these mechanisms just presented are highly speculative in nature, others have suggested similar occurrences $(10,16,17)$.

Another obvious piece of information obtained from this study is the high probability that children with early ABR abnormalities will repeat a grade. These data present a rather convincing picture of impairment that has not only educational impact, but social impact as well.

Several studies have tried to relate pre-, peri-, and postnatal factors to abnormal ABR and developmental outcome $(18,19)$. Although the results have varied widely across risk factors studied, apnea, gestational/conceptional age, and neonatal risk scores have been repeatedly associated with ABR abnormality and developmental outcome. The present study found that, although apnea, gestational age, and cumulative neonatal risk score exhibited differences, adjusted scores were not significant.

The hearing loss results have interesting implications. Although the same two children with sensorineural hearing loss were found in each of the three test groups, the other children with conductive losses differed at 2 and 8 y with one exception. The significant differences seen on reading and spelling measures suggest that mild conductive losses may be contributing to poor performance in these areas. This concept represents an area of controversy that has remained unresolved over the last 20 y (2022). Although it may be tempting to infer from the present study that such a relationship exists, controls appropriate to address this issue were not used. Furthermore, it was not the intent of this study to explore this controversial topic.

In summary, early ABR may predict neurobehavioral development. A note of caution, however, accompanies this predictive potential because the relatively small $n$. In concert with this being the first study to report such findings based on long-term followup, this small $n$ tempers the notion that the ABR can predict developmental outcome. The results do present a picture of consistency that is encouraging.

Acknowledgments. The authors thank Blanche Caron, Margot Bongiovani, Patricia Webb, Suzanne Hawkins, Sharon Cohen, Barbara Weisman, and Nancy Klein for their support.

\section{REFERENCES}

1. Kopp C 1983 Risk factors in development. In: Haith M, Campos J (eds) Handbook of Child Psychology, Vol II. John Wiley, New York, pp 10811188

2. Dunn H 1986 Sequelea of Low Birthweight: The Vancouver Study. J. B. Lippincott, Philadelphia, pp 147-167

3. Kenworthy OT, Bess FH, Stahlman MT, Lindstrom DP 1987 Hearing, speech and language outcome in infants with extreme immaturity. Am J Otolaryngol 5:419-425

4. Klein NK, Hack M, Breslau N, Fanaroff AA 1989 Children who were very low birthweight: achievement at nine years of age. Dev Behav Pediatr 10:3237

5. Broman S, Nichols P, Kennedy W 1975 Preschool IQ: Prenatal and Early Development Correlates. Earlbaum Associates, Hillsdale, NY

6. Siegel L 1983 The prediction of possible learning disabilities in pre- and fullterm children. In: Field T, Sostek A (eds) Infants Born at Risk. Grune \& Stratton, New York, pp 295-315

7. Cox LC 1988 Screening high-risk newborns for hearing loss. Infant Young Child 1:71-81

8. Glassock ME, Jackson CG, Josey AF 1987 The ABR Handbook. Thieme Medical Publishers, New York

9. Majnemer A, Rosenblatt B, Riley P 1988 Prognostic significance of the ABR in high-risk neonates. Dev Med Child Neurol 30:43-52

10. Murray AD 1988 Newborn ABR's: longitudinal correlates in the first year. Child Dev 59:1542-1554

11. Cox LC, Hack M, Metz D 1981 Brainstem evoked response audiometry in the premature infant population. Int $\mathrm{J}$ Pediatr Otorhinolaryngol 3:213-224

12. Hollingshead A, Ridley F 1958 Social Class and Mental Illness. John Wiley, New York

13. Hobel C, Hyvarinen MC, Okada DM, Oh W 1973 Prenatal and intrapartum high-risk screening in prediction of the high risk neonate. Am J Obstet Gynecol 117:1-9

14. Oyler RF, Oyler AL, Matkin ND 1988 Unilateral hearing loss: demographics and educational impact. Lang Speech Hear Serv Schools 19:201-210

15. Bess FH, Klee T, Culbertson J 1986 Identification, assessment, and management of children with unilateral hearing loss. Ear Hear 7:43-51

16. Salamy A, Mendelson T, Tooley WH, Chaplin ER 1980 Differential development of brainstem potentials in healthy and high-risk infants. Science 210:553-555

17. Cox LC 1990 ABR and subsequent development. Hear Inst 41:20-23

18. Murray AD 1988 Newborn ABR's: prenatal and contemporary correlates. Child Dev 59:571-588

19. Henderson-Smart DJ, Pettigrew AG, Campbell DJ 1983 Clinical apnea and brainstem neural function in preterm infants. N Engl $J$ Med 308:353-357

20. Silva P, Chalmers D, Stewart I 1986 Some audiological, psychological, educational and behavioral characteristics of children with bilateral otitis media: a longitudinal study. J Learn Disabil 19:165-169

21. Ventry I 1980 Effects of conductive hearing loss: fact or fiction. J Speech Hear Disord 45:143-156

22. Holm V, Kunze L 1969 Effect of chronic otitis media on language and speech development. Pediatrics 43:833-838 